\title{
The influence of location of the school on school evaluation
}

\section{and investment}

\author{
Wenxing $\mathrm{Hou}^{1, \mathrm{a}}$, \\ ${ }^{1}$ North China Electric Power University, Baoding 071000, China; \\ a773658304@qq.com,
}

Keywords:Fuzzy Clustering Method, City divided

\begin{abstract}
. we classify them into 3 big classes according to the economic development area labeled 1 to 3 by using the fuzzy clustering method. Then we give the regional factor a weight so that the colleges in less developed area can receive more money.

Introduction We find that the top colleges are mainly located in the highly developed area. Therefore, social fairness factor is used to improve our model. We classify the United States into three areas according to the economic development by using the fuzzy clustering method ${ }^{[1]}$. Then we give the regional factor a weight so that the colleges in less developed area can receive more money.
\end{abstract}

\section{Background and significance}

Considering there are too many colleges in the United States,if we create a standard in a same method,it will lack of fairness. What's more, Analytic hierarchy process is not good at dealing with large amount of data,so we decide to improve our model by classifying the colleges from region to region.

The

boundaries between things, some are exact, some are fuzzy ${ }^{[2]}$. Fuzzy clustering method is a mathematical method which involves the fuzzy boundaries between two things according to the certain requirements when classifying things.

Putting the Level of economic development as the most important factors,we decide to use Fuzzy clustering method to classify all the states into 3 groups.The states in different groups have different economic level.When distributing the money,we need to concern about the fairness factor,so the colleges which belong to different groups will get different amount of money,which means the college in a poorer area will get more money. 


\section{Description of Model}

- The first step:On the basis real GDP per capital and gross product of 52 different states, we assume that the domain of discourse $U=\left\{x_{1}, x_{2}, \ldots, x_{29}\right\}$ are the objects to be classified,and every object involves two indexes:

$$
\mathrm{Xi}=\left\{\mathrm{x}_{\mathrm{i} 1}, \mathrm{x}_{\mathrm{i} 2}\right\}(\mathrm{i}=1,2 \ldots 29) \text {. }
$$

Then we can get a original matrix $\mathrm{X}=\left(\mathrm{X}_{\mathrm{ij}}\right)_{29 \times 2}$, since these two indexes have the same dimension,we can save the step of normalization. ${ }^{[3]}$

- The second step: Use distance method to establish fuzzy similar matrix.

To confirm the similar degree of $\mathrm{x}_{\mathrm{i}}$ and $\mathrm{x}_{\mathrm{j}}$, We use the main method Euclidean distance:

$$
\mathrm{d}\left(\mathrm{x}_{\mathrm{i}}, \mathrm{x}_{\mathrm{j}}\right)=\sqrt{\sum_{k=1}^{2}\left(x_{i k}-x_{j k}\right)^{2}}
$$

Then we get the similar matrix:

$$
r_{i j}=1-c d\left(x_{i}, x_{j}\right)
$$

Where c is a appropriate parameter which makes:

$$
0 \leq r_{i j} \leq 1
$$

Here we define $\mathrm{c}=0.015$.

- The third step:cluster

Use the fuzzy similar matrix from the second step,then we use the collecting data about the economic development about the states,we can get a dynamic clustering figure.

\section{Model Solving}

By using this method,we can divide 52 states into 3 groups,the result is shown in the following table.

We carry on the sorting of the states according to the state's total GDP . We divide the top 17 states, the middle and the last 17 states into three groups, numbered 1, 2, 3 . The result is shown in the following form. 
Form 1 States Divided by the Economic Factor

\begin{tabular}{|c|c|c|c|c|c|}
\hline Catego & Category & States & Category & \multicolumn{2}{|c|}{ Category } \\
\hline California & 1 & Missouri & 2 & Utah & 3 \\
\hline New York & 1 & Wisconsin & 2 & Nebraska & 3 \\
\hline Texas & 1 & Tennessee & 2 & New-Mexico & 3 \\
\hline Florida & 1 & Colorado & 2 & New-Hampshire & 3 \\
\hline Illino is & 1 & Connecticut & 2 & West-Virginia & 3 \\
\hline Penns ylvania & 1 & Arizona & 2 & $\mathrm{H}$ a $\mathrm{w}$ a $\mathrm{i}$ i & 3 \\
\hline $\mathrm{N}$ e w - J e rs e y & 1 & L o u is i an a & 2 & $\mathrm{M}$ a $\mathrm{i} n \mathrm{e}$ & 3 \\
\hline O h i o & 1 & A labama & 2 & $\begin{array}{lllll} & d & a & h & o\end{array}$ & 3 \\
\hline M i c hig a n & 1 & South-Carolina & 2 & Rhode-Island & 3 \\
\hline Massachusetts & 1 & Kentucky & 2 & Delaware & 3 \\
\hline G e org i a & 1 & Oregon & 2 & District-of-Columbia & 3 \\
\hline Virginia & 1 & Oklahoma & 2 & Montana & 3 \\
\hline North-Carolina & 1 & I o w a & 2 & Alaska & 3 \\
\hline Was hington & 1 & Kansas & 2 & South-Dakota & 3 \\
\hline Maryland & 1 & $\mathrm{Nevada}$ & 2 & Vermont & 3 \\
\hline I n d i a n a & 1 & Mississippi & 2 & North-Dakota & 3 \\
\hline Minnesota & 1 & Arkansas & 2 & Wy o m ing & 3 \\
\hline
\end{tabular}

We label it on the following picture,the color red means the most developed area,the green ones represent the relatively developed area,the blue ones represent the less developed area.

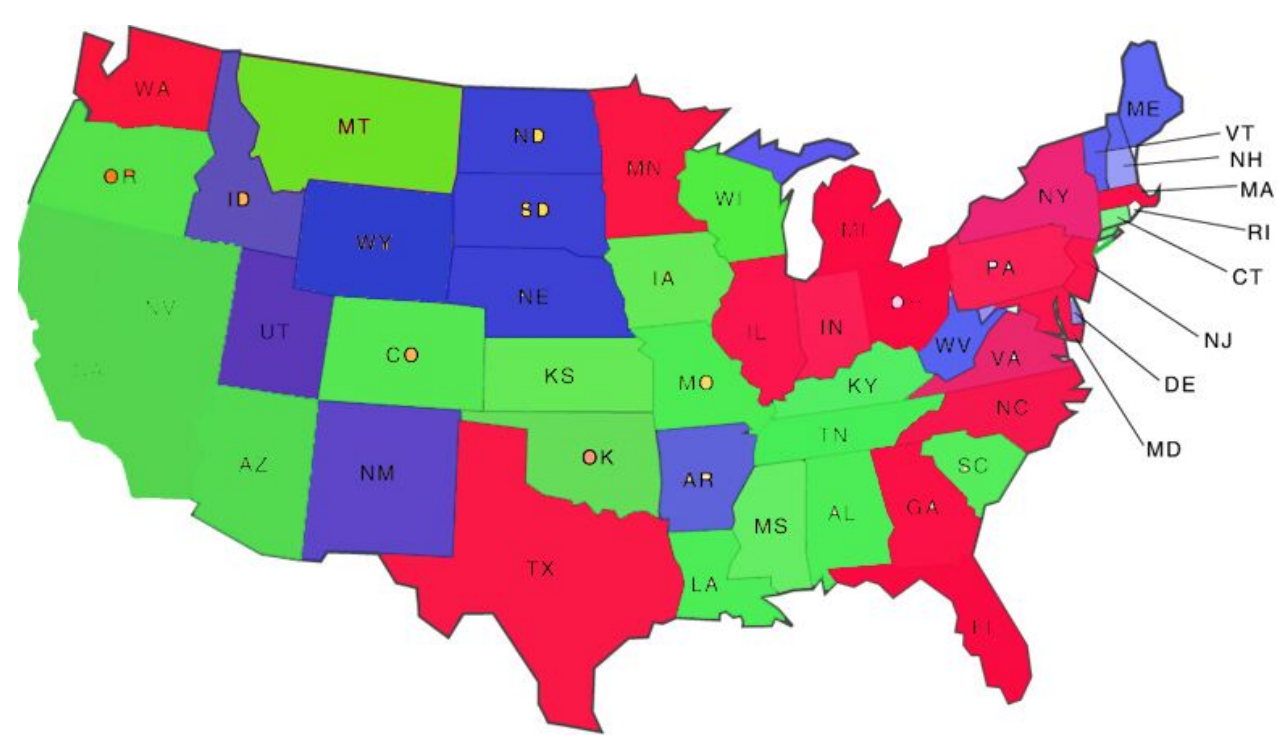

Picture 1 States division according to the economic development 
Analysis the result from the table,we can know that:

(1)The most developed areas are mainly located in the eastern coast of America.We label area ' 1 '.

(2)Relatively developed areas are mainly located in the middle of America.we label area ' 2 '.

(3)The less developed areas are mainly located in the northwest of America.We label area ' 3 '.

Considering the fairness factor,we put these colleges into these 3 groups,and we sort the colleges according to the comprehensive index that we get above.Then we distribute money to these three groups differently,we will give the area labeled ' 3 ' the most amount of money,then the label ' 2 ',the label ' 1 '.

\section{Summary}

By using Fuzzy Clustering Method to City divided, we can evaluate school and have a certain significance to the investment for school ${ }^{[4]}$. Our model can be practically used in different fields to evaluate things from various aspects. And The influence of The location of the school on the school evaluation and investment is significant.

\section{References}

[1] Lv Yongxia yong-cheng, NieLi. Fuzzy cluster analysis of the urban economy development of Yangtze river delta [J]. Journal of guangxi academy of sciences, 2006, 22 (3) : 167-170.

[2] Xinbo Gao, Fuzzy cluster analysis and its application [M]. Cambridge university press, 2004.

[3]Chengping Liu,Mathematical modeling method,Beijing,Higher Education Press,2002.

[4]Wang Hongke Yuan Yuxing. Research on China's biggest cities divided level, based on the city line Q type cluster and principal component analysis [J]. Journal of chongqing institute of technology (social science edition), 2013 (1) : 71-73. 